\title{
Primary Structure, Neural-Specific Expression, and Dendritic Location of Human BC200 RNA
}

\author{
Henri Tiedge, Wei Chen, and Jürgen Brosius \\ Fishberg Research Center for Neurobiology, Mount Sinai School of Medicine, New York, New York 10029
}

Primate BC200 RNA is a 200-nucleotide-long, nontranslatable RNA that is prevalently expressed in the nervous system. We have determined the primary structure of human BC200 RNA, using CDNA cloning and PCR techniques. BC200 RNA can be subdivided into three structural domains. The $5^{\prime}$ region is homologous to Alu repetitive elements that are found in high copy numbers in primate genomes. The central part of BC200 RNA is characterized by a high percentage of A-residues, with a few interspersed other nucleotides. The 3 ' s'equence is unique to BC200 RNA and shows no apparent similarity with known human DNA sequences. Sequence similarity with rodent BC1 RNA is limited to several short elements, and $\mathrm{BC} 1 / \mathrm{BC} 200$ sequence comparisons indicate that the two genes have evolved via separate phylogenetic routes. Probes directed against the $3^{\prime}$ unique part of BC200 RNA detected a single band corresponding to approximately 200 nucleotides on RNA blots. This band was identified only with RNA isolated from human brain, not with RNA from nonneural organs such as lung or kidney. In situ hybridization to selected areas of the human nervous system showed that BC200 RNA is expressed by a subpopulation of neurons that is analogous to the BC1 RNA-expressing subset of neurons in the corresponding areas of the rat nervous system. Moreover, like rat BC1 RNA, human BC200 RNA was localized to dendrite-rich neuropil areas, for example, in the inner plexiform layer of the retina. These results indicate that BC1 RNA and BC200 RNA, although of different evolutionary pedigree, may play analogous functional roles, in rodents and primates, respectively, in somatodendritic domains of nerve cells.

[Key words: dendritic RNA, dendritic protein synthesis, nonmessenger RNA, human nervous system, cDNA cloning, in situ hybridization]

The concept of localized protein synthesis in dendrites has received increasing experimental support in the past years (see Steward and Banker, 1992, for review). Thus, it has been shown that polyribosomes are located beneath synaptic sites, in par-

\footnotetext{
Received Aug. 11, 1992; revised Nov. 25, 1992; accepted Dec. 7, 1992.

We thank Dr. P. Gouras for the human retinas, and Drs. N. Broude and P. Hof for several samples of human brain tissue. We are indebted to Dr. R. Cate and S. Klco for their expert help in genomic Southern experiments. The GAP-43 cDNA clone that was used in this study was a gift of Dr. R. Neve. R. Woollcy and P. Male assisted in the processing of photographs. This work was supported by NIH (MH38819 to J.B.) and the Deutsche Forschungsgemeinschaft (HT 161/1-1 to H.T.).

Correspondence should be addressed to Henri Tiedge and Jürgen Brosius, Fishberg Research Center for Neurobiology, Mount Sinai School of Medicine, One Gustave L. Levy Place, New York, NY 10029.

Copyright (C) 1993 Society for Neuroscience $0270-6474 / 93 / 132382-09 \$ 05.00 / 0$
}

ticular at the base of dendritic spines, in dentate granule cells of the hippocampus (Steward and Levy, 1982; Steward and Reeves, 1988). Dendritic polyribosomes are particularly prominent during periods of developmental and reactive synaptogenesis (Steward, 1983; Steward and Falk, 1986). The accumulation of polyribosomes within dendritic spines of the visual cortex has been shown to be substantially higher in rats reared in complex environments than in control littermates (Greenough et al., 1985). Furthermore, it has been demonstrated that RNA is actively transported into dendrites but not into axons of hippocampal neurons in culture (Davis et al., 1987, 1990).

The mRNAs for a limited number of dendritic proteins have been detected in dendrites at significant levels. One of them codes for the high-molecular-mass form of microtubule-associated protein MAP2 (Garner et al., 1988; Papandrikopoulou et al., 1989; Tucker et al., 1989; Bruckenstein et al., 1990; Kleiman et al., 1990), another one for the $\alpha$-subunit of $\mathrm{Ca}^{2+} / \mathrm{cal}$ modulin-dependent protein kinase type II (CaM-KII) (Burgin et al., 1990; Benson et al., 1991). High-molecular-mass MAP2 is a tubulin-binding protein specifically associated with the dendritic cytoskeleton (see Cleveland, 1990, for a review). CaMKII is highly enriched in postsynaptic densities and may be involved in signal transduction mechanisms and in the induction of long-term potentiation (for a review, see Kennedy, 1989). Furthermore, the mRNA for the amyloid precursor protein (APP) has been detected in proximal dendritic domains of developing hippocampal neurons in culture (Strong et al., 1990), and recently, the mRNA encoding brain-derived neurotrophic factor (BDNF) has been identified in proximal dendritic segments of dentate granule cells during postnatal development (DugichDjordjevic et al., 1992).

Dendritic mRNAs have been detected in hippocampal synaptosome preparations (also referred to as "synaptodendrosomes") that had been enriched in dendritic spine material (Chicurel et al., 1991). Active protein biosynthesis has recently been demonstrated in preparations of synaptosomes (Rao and Steward, 1991) as well as in preparations of dendrites that had been physically isolated from hippocampal neurons in culture (Torre and Steward, 1992). These data provide important support for the hypothesis that nerve cells are capable of synthesizing selected dendritic proteins locally, close to the respective postsynaptic sites where they are required. Such a mechanism may enable neurons to regulate dendritic protein repertoires in situ, for example, in response to local synaptic stimuli.

Rat BC1 RNA is a short RNA polymerase III transcript that is almost exclusively expressed in nerve cells (DeChiara and Brosius, 1987; McKinnon et al., 1987; Tiedge et al., 1991). BC1 RNA has been detected in a subset of neurons where it is located in somatic and/or dendritic domains, and its dendritic location 
has been suggested to indicate a functional role in postsynaptic compartments of neurons, conceivably in the context of local translation-related processes (Tiedge et al., 1991). Recent data (Kobayashi et al., 1991, 1992; Cheng et al., 1992) suggesting that BC1 RNA is likely to be complexed with proteins to form a ribonucleoprotein particle (RNP) would be consistent with such a notion. It has also been shown recently that BC1 RNA is a prominent component of isolated dendritic spines (M. Chicurel, D. M. Terrian, and H. Potter, personal communication) and synaptodendrosomes (A. Rao and O. Steward, personal communication), where it is colocalized with dendritic mRNAs. This colocalization is further evidence to support a role of $\mathrm{BCl}$ RNA in synapse-associated protein synthesis.

While a direct $\mathrm{BCl}$ homolog has not been described in primates, a partial cDNA sequence from monkey BC200 RNA, also a brain-specific RNA polymerase III transcript, has been reported earlier (Watson and Sutcliffe, 1987). However, because of the extensive homology of this sequence with the highly repetitive Alu elements, probes that would specifically identify BC200 RNA were not available, and as a result, the expression of this RNA in the human nervous system and its subcellular distribution could not be assessed. Here we report the sequence, including the unique (non-Alu) $3^{\prime}$ part, of human BC200 RNA. Using probes against the unique part of BC200 RNA, we describe its distribution in human neural tissue. Although of limited sequence similarity with its rat counterpart BCl RNA, human BC200 RNA exhibits a strikingly similar expression pattern in selected parts of the human nervous system. In addition, we show that $\mathrm{BC} 200 \mathrm{RNA}$, comparable again to rat $\mathrm{BC} 1$ RNA, is associated with both somatic and dendritic domains of various types of neurons. These data indicate that both RNAs, although presumably of separate phylogenetic background, may perform analogous functional roles in postsynaptic domains of nerve cells.

\section{Materials and Methods}

Cloning of human BC200 RNA. Total cellular RNA and polyA+ RNA were isolated from human neocortex according to the method of Feramisco et al. (1982). Five micrograms of polyA ${ }^{+}$RNA were tailed with CTP, using polyA polymerase, and the C-tailed RNA was converted into double-stranded cDNA as previously described (DeChiara and Brosius, 1987). EcoRI-adaptors (Pharmacia) were attached, according to the instructions of the manufacturer, and cDNA smaller than about 400 base pairs was selected on a $4 \%$ polyacrylamide gel. Electro-eluted cDNA was cloned into $\lambda Z A P$ (Stratagene), following the manufacturer's manual. We screened $3.6 \times 10^{4}$ plaques with an oligonucleotide probe complementary to the sixty $3^{\prime}$-most nucleotides of rat $\mathrm{BCl}$ RNA (DeChiara and Brosius, 1987; Tiedge et al., 1991) at low stringency (final wash at $35^{\circ} \mathrm{C}$ in $6 \times \mathrm{SSC} ; 1 \times \mathrm{SSC}$ is $150 \mathrm{~mm}$ sodium chloride, 15 mM sodium citrate, $\mathrm{pH} 7.4$ ). Four clones were identified as positive, and the sequences of their inserts (both strands) were determined using the enzymatic chain termination reaction (Sanger et al., 1977; Toneguzzo et al., 1988). Twelve additional clones were later identified and sequenced after rescreening of the library with oligonucleotide probes complementary to specific BC200 RNA sequences (see below).

$P C R$ amplification of $5^{\prime}$ and $3^{\prime}$ domains of BC200 RNA. For amplification of the $5^{\prime}$ BC200 sequence, $1 \mu \mathrm{g}$ total RNA from human neocortex was converted into first-strand CDNA using the thermostable rTth DNA polymerase (Perkin Elmer Cetus) according to the instructions of the manufacturer. The primer used in this step was $5^{\prime}$ GTTGTTGCTTTGAGGGAAG-3' (WC001). The 3' end of the product was then T-tailed using dTTP and terminal transferase (Boehringer Mannheim). The tailed cDNA was PCR amplified (Frohman et al., 1988 ) in 30 cycles (denaturation for $30 \mathrm{sec}$ at $94^{\circ} \mathrm{C}$, annealing for $1 \mathrm{~min}$ at $55^{\circ} \mathrm{C}$, extension for $2 \mathrm{~min}$ at $72^{\circ} \mathrm{C}$; initial denaturation was for $4 \mathrm{~min}$ at $94^{\circ} \mathrm{C}$, final extension was for $10 \mathrm{~min}$ at $72^{\circ} \mathrm{C}$ ), using the primers $5^{\prime}$ GCCTTCGAATTCAGCACCGAGGGAAGTTACGCTTA-3' (WC-
004), and 5'-GCCTTCGAATTCAGCACCAAAAAAAAAAAAAAAAA-3' (HT021). The products were further amplified in a second set of 30 cycles (for conditions, see above), using the adapter primer 5 GCCTTCGAATTCAGCACC-3' (HT023). After digestion with EcoRI, the PCR products were cloned into the EcoRI site of $\lambda Z A P I I$ (Stratagene) following the manual of the manufacturer; $10^{3}$ plaques were screened with an internal oligonucleotide probe 5'-AAAAAAAAA(T/A)(T/ G)GCCGGGCGCGGT-3' (WC007), and six positive clones were sequenced.

For amplification of the $3^{\prime}$ BC200 sequence, $10 \mu \mathrm{g}$ total RNA from human neocortex was A-tailed using polyA polymerase (DeChiara and Brosius, 1987). Tailed RNA was then converted into first-strand cDNA with reverse transcriptase in the presence of $\mathrm{MeHgOH}$ (Invitrogen), using the primer $5^{\prime}$-GCCTTCGAATTCAGCACCTTTTTTTTTTTTTTTTT-3' (HT022). This primer, in combination with the primer 5 -GCCTTCGAATTCAGCACCAAAATAAGCGTAACTTCCC-3' (WC005), was also used for PCR amplification (see above). Products were cloned into $\lambda Z A P I I$ (see above), and 14 clones that were identified with WC005 were sequenced using the enzymatic chain termination reaction.

DNA and RNA blots. Human genomic DNA was prepared from human blood (Smith et al., 1988). Southern analysis of genomic DNA was performed as described by Devlin et al. (1988). The oligonucleotide probe was complementary to the sequence 5'-AAATAAGCGTAACTTCCCTCAAAGCAACAA-3' in the $3^{\prime}$ unique domain of $\mathrm{BC} 200$ RNA, and the final wash was done at $70^{\circ} \mathrm{C}$ (high stringency) or at $56^{\circ} \mathrm{C}$ (low stringency). For RNA blots, $10 \mu \mathrm{g}$ of total cellular RNA was run per lane on a $1.5 \%$ agarose gel containing $2 \%$ formaldehyde (Sambrook et al., 1989). The RNA was transferred onto GeneScreen membranes (New England Nuclear) and immobilized by UV illumination (Church and Gilbert, 1984). The oligonucleotide probe used for detection of BC200 RNA on RNA blots was complementary to the $3^{\prime}$ unique $\mathrm{BC} 200$ sequence 5'-ATAAGCGTAACTTCCCTCAAA-3'. The BCl oligonucleotide probe was complementary to the sixty $3^{\prime}$-most nucleotides of BC1 RNA (see above). Hybridization was performed as described by Sambrook et al. (1989), and the final wash was in $2 \times \mathrm{SSC}$ at $30^{\circ} \mathrm{C}$.

In situ hybridization. Human tissue (postmortem intervals $<6 \mathrm{hr}$ ) was formaldehyde-fixed and equilibrated in a series of ascending sucrose concentrations as described (Hof and Morrison, 1990). The tissue was then cryo-embedded, sectioned at $10 \mu \mathrm{m}$ thickness at $-20^{\circ} \mathrm{C}$, and stored at $-80^{\circ} \mathrm{C}$ until use.

Probes used to detect human BC200 RNA in in situ hybridization experiments were equivalent to the oligonucleotide probe used for DNA blots and corresponded to the sequence 5'-AAATAAGCGTAACTTCCCTCAAAGCAACAA-3' in the $3^{\prime}$ unique domain. A transcription vector ( $\mathrm{pVL} 450-1$ ) containing this sequence was constructed by inserting a chemically synthesized piece of DNA with the appropriate restriction site termini between the KpnI and the SacI sites of pBluescrip $\mathrm{KS}(+)$ (Stratagene). A transcription vector for generating probes specific for GAP-43 mRNA has been described earlier (Neve et al., 1988). ${ }^{35} \mathrm{~S}$ labeled RNA probes were transcribed from linearized templates, using SP6 (GAP-43 mRNA "antisense"), T3 (BC200 RNA "sense"), and T7 RNA polymerase (BC200 RNA "antisense", GAP-43 mRNA "sense") as recommended by the manufacturers (Promega and Bethesda Research Labs).

In situ hybridization was performed as described (Tiedge, 1991). The final high-stringency wash was in $0.1 \times \mathrm{SSC}, 0.05 \%$ sodium pyrophosphate, $14 \mathrm{mM} 2$-mercaptoethanol, at $37^{\circ} \mathrm{C}$ (BC200 RNA) or $50^{\circ} \mathrm{C}$ (GAP-43 mRNA), respectively. Posthybridization treatments, emulsion autoradiography, and microphotography have been described earlier (Fremeau et al., 1989; Tiedge, 1991).

\section{Results}

\section{Cloning of human BC200 RNA}

The results of initial RNA blot experiments indicated that a probe complementary to the $3^{\prime}$ unique part of rat $\mathrm{BCl}$ RNA identified a transcript of about 200 nucleotides in RNA isolated from human brain (Fig. 1 $A$ ). This transcript was detectable in total RNA and in polyA ${ }^{+}$RNA, but not in polyA- RNA. We reasoned that the structure of the human transcript might be equivalent to rat $\mathrm{BC} 1 \mathrm{RNA}$ in that an A-rich domain is centrally located in the RNA (DeChiara and Brosius, 1987), not $3^{\prime}$-most 
A B

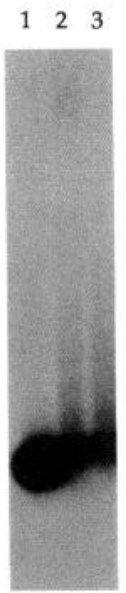

$\mathrm{C}_{\mathrm{P}}$

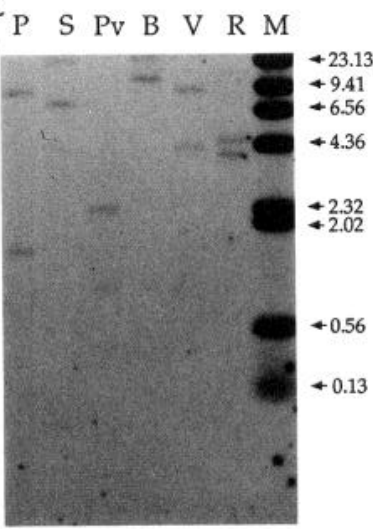

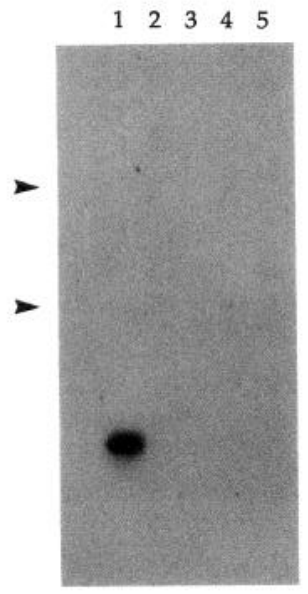

$D$

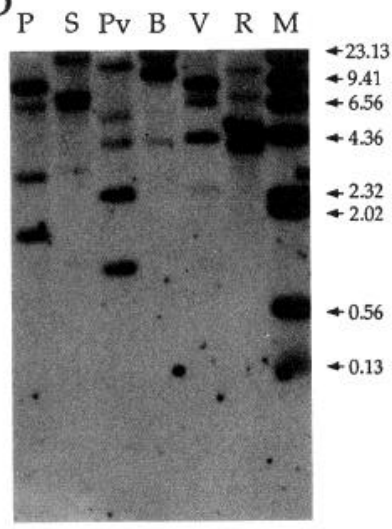

Figure 1. RNA and DNA blot analysis of human BC200 RNA. $A$ and $B$, RNA blot analysis. $A$, Ten micrograms of total RNA from rat brain (lane 1) and from human neocortex (lanes 2 and 3 ) were run on a $1.5 \%$ denaturing agarose gel. RNA loaded in lanes 2 and 3 was from two different preparations. The oligonucleotide probe was complementary to the sixty $3^{\prime}$-most nucleotides of rat $\mathrm{BC} 1 \mathrm{RNA}$. $B$, Ten micrograms of total RNA from human neocortex (lane 1), from human lung (lanes 2 and 3), and from human kidney (lanes 4 and 5) were probed with an oligonucleotide complementary to the unique BC200 sequence. Duplicate samples correspond to different preparations. Equal loading was verified by visualization of ribosomal RNA under UV light (not shown). Arrowheads indicate the positions of 28S rRNA (upper arrowhead) and $18 \mathrm{~S}$ rRNA (lower arrowhead). $C$ and $D$, Southern analysis of genomic DNA. Forty micrograms of human genomic DNA were digested with PstI $(P)$, SacI $(S)$, PvuII $(P v)$, BamHI $(B)$, EcoRV $(V)$, and EcoRI $(R)$ respectively. Twenty micrograms of each digest were run on a $1 \%$ agarose gel, transferred to filters, and hybridized according to Devlin et al. $(1988)$. Duplicate filters were washed at $70^{\circ} \mathrm{C}(C)$ or at $56^{\circ} \mathrm{C}(D) ; \lambda$ fragments, generated by HindIII digestion of $\lambda$ DNA, were radiolabeled and loaded as size markers in lane $M$.

as in a typical mRNA. We therefore used polyA polymerase to add an oligoC tail to the $3^{\prime}$ end of polyadenylated RNA from human brain, and we constructed a cDNA library after priming with oligo-dG, thereby avoiding unwanted priming in the center of the RNA. The cDNA library was subsequently screened with an oligonucleotide probe complementary to the sixty $3^{\prime}$-most nucleotides of rat BC1 RNA.

The validity of this approach was confirmed by the sequence of human BC200 RNA (Fig. 2). These data were obtained by sequence analysis of 16 overlapping clones, and no sequence

discrepancies were observed among these clones except for the length of homopolymeric A- and C-tracts. The variable length of homopolymeric regions is most likely due to errors during cDNA synthesis (DeChiara and Brosius, 1987), and Figure 2 gives the length of such tracts as derived from sequence analysis of a subsequently isolated genomic clone (J. A. Martignetti and J. Brosius, unpublished observations).

Like rat BC1 RNA, human BC200 RNA can be subdivided into three major structural domains (Fig. 2). The $5^{\prime}$ part (120 nucleotides) shares homology with a previously published partial cDNA sequence from cynomolgus monkey BC200 RNA (Watson and Sutcliffe, 1987), and it is furthermore homologous to the left monomer of Alu-J repetitive elements (Willard et al., 1987) and to free left Alu monomers (Jurka and Zuckerkandl, 1991; Quentin, 1992) in the human genome. The 5' domain contains consensus elements A and B of the split RNA polymerase III promoter (Galli et al., 1981), as well as two sequence elements that have recently been identified as the consensus motifs in signal recognition particle (SRP) RNA (see Walter and Blobel, 1982) for the binding of SRP heterodimeric protein 9/14 (boxes 1 and 2 of SRP9/14 binding site IIB; Strub et al., 1991). The $5^{\prime}$ domain is followed by a central A-rich region, which in turn is followed by a stretch of 42 nucleotides at the $3^{\prime}$ end of the RNA. This $3^{\prime}$ sequence is unique to $\mathrm{BC} 200 \mathrm{RNA}$ : computer searches failed to detect any significant similarity with DNA sequences compiled in the GenBank/EMBL Data Bank. In addition, Southern analysis of genomic DNA revealed only two bands when a probe against the 3' part was used at high stringency (see below). The unusual C-tract in the $3^{\prime}$ domain has also been detected in a genomic clone and is therefore unlikely to be the result of posttranscriptional modification.

Only two out of 16 cDNA clones showed 3'-terminal T-residues following the internal C-tract (see Fig. 2 and below), and all of the clones varied with respect to their $5^{\prime}$-terminal sequence extent. Thus, in order to verify the extreme $5^{\prime}$ and $3^{\prime}$ sequences of BC200 RNA, we devised amplification schemes, based on PCR in combination with enzymatic tailing procedures. For the determination of the $5^{\prime}$ sequence, RNA isolated from human brain was reverse transcribed, using oligonucleotide WC001 as a primer, and first-strand cDNA was tailed with dTTP, using terminal transferase. For the determination of the 3 ' sequence, brain RNA was tailed with ATP, using polyA polymerase, and then converted into first-strand cDNA by reverse transcriptase. The cDNAs were then amplified, cloned into a $\lambda$ vector, identified with internal oligonucleotide probes, and sequenced as described in Materials and Methods. All cDNA clones obtained in this way were colinear with corresponding parts of our original cDNA clones, obtained by library screening, and with corresponding parts of a subsequently isolated genomic clone. The $5^{\prime}$ terminal sequence of BC200 RNA was determined from six independent clones, obtained by the PCR-based method (see Fig. 2); it is identical with the $5^{\prime}$ sequence of cynomolgus BC200 RNA (Watson and Sutcliffe, 1987), but falls one nucleotide short of the $5^{\prime}$ end of SRP RNA (Ullu et al., 1982), and two nucleotides short of the 5' end of Alu elements (Jurka and Milosavljevic, 1991). This result may be explained by (1) different transcriptional start sites in BC200 RNA versus SRP RNA, (2) differential posttranscriptional modification in vivo, or (3) inefficient reverse transcription of distal $5^{\prime}$ nucleotides in vitro, prior to the tailing and amplification steps. At the $3^{\prime}$ end of $\mathrm{BC} 200 \mathrm{RNA}$, a stretch of maximally three T-residues was identified in PCR amplification products, thus confirming the sequence of the 3 '- 


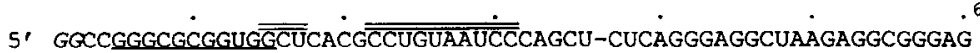

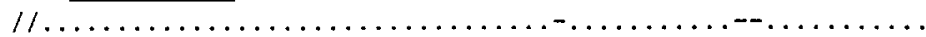

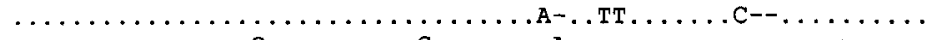
$-\ldots \ldots \ldots \ldots \ldots$.g.gu.....G...............-.......

GAUAGCUUGÄGCCCAGGAGUUCGAGACCUGCCUGGGCAAUAUAGCGAGACCCCGUUCUCCAG ${ }^{12}$

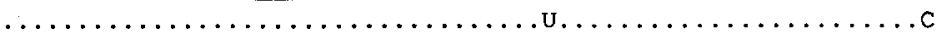

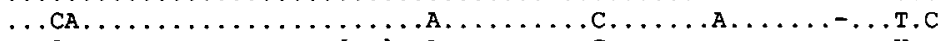
$\ldots$............. [ ]..................

158

AAAAAGGAAAAAAAAAAAC-AAAAGACAAAAAAAAAA

......./I

..... Ат.С.....

$\ll \ldots$ U...A..............
hBC200 RNA; Domain I, nt 1 - 122: Alu-homologous mBC200 RNA

Alu-J left monomer

SRP RNA

\section{hBC200 RNA}

$\mathrm{mBC} 200$ RNA

Alu-J left monomer

SRP RNA

hBC200 RNA; Domain II, nt 123 - 158: A-rich

mBC200 RNA

Alu-J left monomer

rBC1 RNA

hBC200 RNA; Domain III, nt 159 - 200: BC200-unique
rBC1 RNA
UAAGCGUAACUUCCCUCAAAGCA--ACAACCCCCCCCCCCCUUUU ${ }^{200} 3^{\prime}$

C. . . . . . . . . . . . . . . . $\gg>$

Figure 2. Sequence of unmodified BC200 RNA as deduced from cDNA clones and PCR amplification products. Sixteen overlapping cDNA clones were analyzed. Overlapping sequences were identical except for length heterogeneity in the homopolymeric A-lracts in domain II and the homopolymeric C-tract in domain III. The length of the homopolymeric tracts shown here was based on sequence information from a genomic clone (Martignetti and Brosius, unpublished observations). The sequence of the genomic clone is $100 \%$ colinear with the human BC200 RNA sequence shown here. Nucleotide 7 was the 5'-most nucleotide that was obtained through sequencing of cDNA clones. Nucleotides 3-6 were determined by sequence analysis of PCR-amplified BC200 domains (see Results). The sequence of nucleotides 1 and 2 (in italics) was adopted from a genomic clone and is identical to the published 5' sequence of Alu-J repetitive elements. Nucleotide 1 corresponds to the $5^{\prime}$-most nucleotide of Alu elements, and nucleotide 2 corresponds to the 5'-terminal nucleotide of SRP RNA. The cDNA clone that extended 3'-most ended with three thymidine residues, followed by a stretch of cytidine residues that corresponds to the enzymatically added C-tail (not shown here). Clones obtained through tailing and PCR amplification also showed a maximum of three T-residues at the $3^{\prime}$ end. The fact that most of the original cDNA clones showed no 3' T-residues is probably attributable to oligo-dG priming at the internal C-tract rather than at the enzymatically added C-tract. The consensus sequence of the split RNA polymerase III promoter (boxes A and B) is underlined, and elements corresponding to boxes 1 and 2 of SRP9/14 binding site IIB in SRP RNA are double overlined (see also Results). Sequences other than human BC200 RNA are given only insofar as they differ from that sequence. Dots denote sequence identity with human BC200 RNA, and dashes denote gaps that were introduced in order to increase similarity. Double slashes (/) demarcate the ends of available monkey BC200 sequence. Double arrows ( $\ll$ or $\gg$ ) indicate the ends of sequence similarity of the left monomer of Alu-J or of rat BCl RNA, respectively, with human BC200 RNA. The sequence of 103 nucleotides of BCl RNA that lies $5^{\prime}$ to the sequence shown here contains a stretch that is homologous to the repetitive ID elements in the rat genome (DeChiara and Brosius, 1987). Space in brackets ([ ]) represents the central part of SRP RNA (187 nucleotides, positions 80-266) that is not homologous to the Alu-J left monomer. The last U residue given for SRP RNA is the 3' terminus. The SRP RNA sequence chosen here corresponds to the 7L30.1 locus that represents an authentic gene of human SRP RNA (Ullu and Weiner, 1984). Lowercase letters were used when any of the additional available human subforms or other mammalian SRP RNAs (Zwieb and Nielsen, 1992) show identity with BC200 RNA in that position. hBC200 RNA, human BC200 RNA; $m B C 200 R N A$, monkey BC200 RNA; $r B C 1 R N A$, rat BC1 RNA.

most extending cDNA clone (Fig. 2). A genomic clone showed four T-residues at this position, a motif likely to represent a transcription termination signal for RNA polymerase III (Bogenhagen and Brown, 1981).

A partial cDNA sequence from cynomolgus monkey BC200 RNA has been reported earlier (Watson and Sutcliffe, 1987). The monkey sequence is highly homologous to the $5^{\prime}$ domain of human BC200 RNA as described in this article (see Fig. 2). In the previous report, however, no sequence information was available about the central A-rich domain or the $3^{\prime}$ unique domain of BC200 RNA. Thus, because of the homology of the $5^{\prime}$ part with Alu repetitive elements, suitable probes were lacking to identify specific $\mathrm{BC} 200$ sequences. In the following, we use probes specific to the unique $3^{\prime}$ part of $\mathrm{BC} 200$ RNA in order to probe neural and non-neural organs for the presence of $\mathrm{BC} 200$ RNA, to identify $\mathrm{BC} 200$ genes in genomic DNA blot analyses, and to localize BC200 RNA in human neural tissue.

We designed oligonucleotide probes complementary to parts of the unique $3^{\prime}$ domain of human BC200 RNA (see Materials and Methods). On RNA blots, a transcript of an apparent length of about 200 nucleotides was identificd in RNA from human brain (Fig. 1B). Little or no specific labeling was evident in lanes that were loaded with RNA from human lung or kidney (Fig. $1 B$ ) or from other human organs such as breast, bladder, colon, or liver; a weak signal was, however, observed with RNA from human testis (not shown). These results indicate that the overall tissue distribution of human BC200 RNA is similar to the tissue distribution of both monkey $\mathrm{BC} 200 \mathrm{RNA}$ and rat $\mathrm{BC1}$ RNA. These RNAs have been shown to be absent from non-neural organs such as liver, spleen, kidney, skeletal muscle, and others (DeChiara and Brosius, 1987; McKinnon et al., 1987; Watson and Sutcliffe, 1987). Using oligonucleotides specific to the $3^{\prime}$ part of BC200 RNA in genomic DNA blot analyses, we identified two bands under high-stringency conditions (Fig. 1C, D). This result indicates that maximally two BC200 RNA genes are present in the human genome.

\section{Expression of BC200 RNA in human neural tissue}

The distribution of human BC200 RNA in selected neural tissues was examined using in situ hybridization techniques. The ${ }^{35}$ S-labeled RNA probes that were generated for these experiments again corresponded to part of the unique $3^{\prime}$ domain of BC200 RNA (see Materials and Methods). A probe complementary to this part of BC200 RNA ("antisense" probe) and a "sense" strand control probe were used in parallel. The control probe failed to produce specific labeling in any of the examined tissues (see below). 


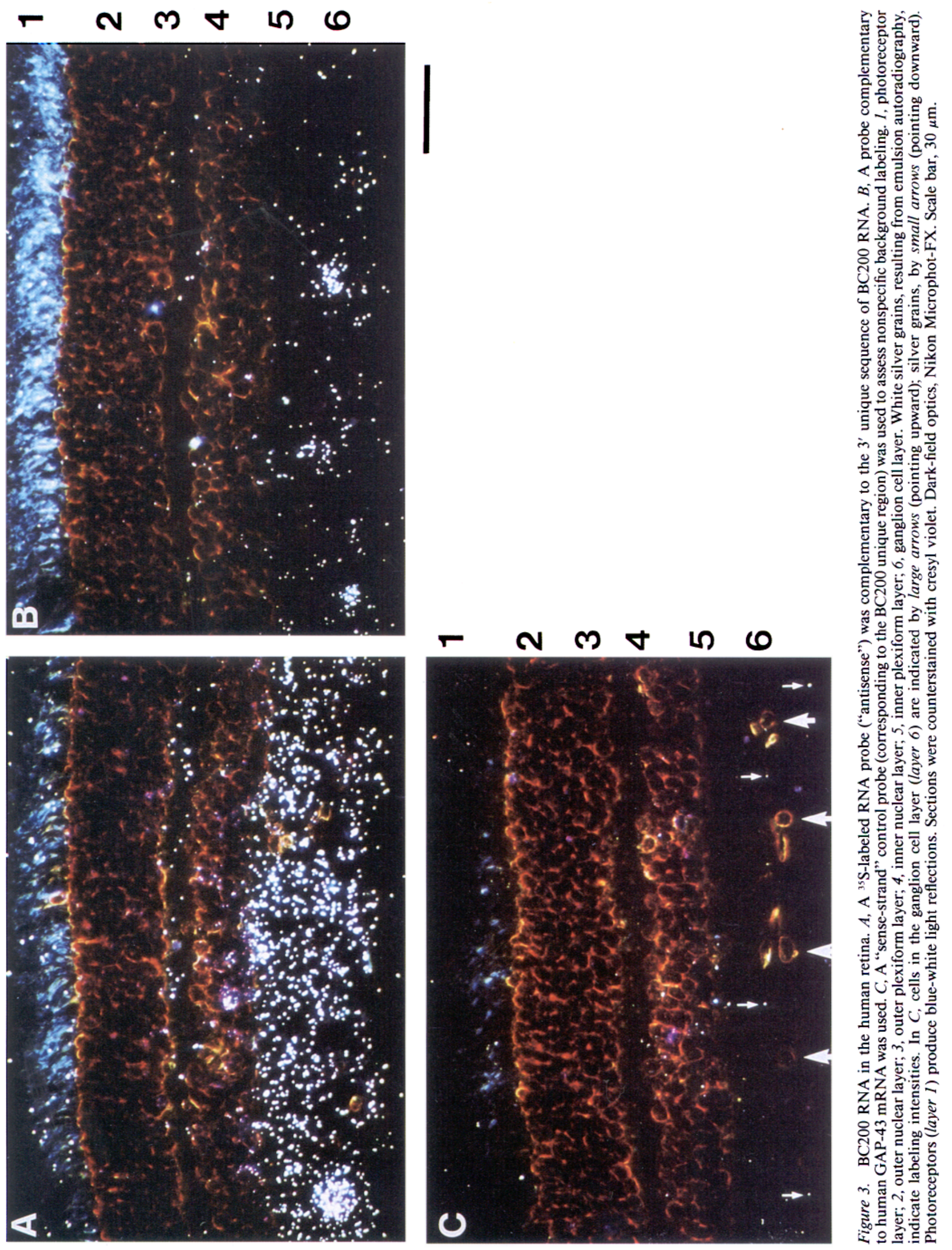


The BC200 RNA labeling pattern in the human retina is shown in Figure 3. Labeling was restricted to the ganglion cell layer, the inner plexiform layer, and the innermost layer of the inner nuclear layer. Other layers, for example, the photoreceptor cell layer, showed little or no labeling above background, and the overall labeling pattern is thus similar to the one obtained for BCl RNA in the rat retina (Tiedge et al., 1991). While the majority of the neurons in the ganglion cell layer seemed to be intensely labeled, few cells in the inner nuclear layer were identified by the BC200 RNA probe. The labeled neurons in the ganglion cell layer and in the innermost layer of the inner nuclear layer most likely belong to the class of ganglion cells and amacrine cells, respectively, possibly including displaced individuals of either class (Ramón y Cajal, 1892). Substantial BC200 labeling was also observed in the inner plexiform layer, the dendritic territory of ganglion cells and amacrine cells (Dowling and Boycott, 1966). As with rat BCl RNA, this result indicates a somatodendritic location of human BC200 RNA.

The expression pattern of $\mathrm{BC} 200 \mathrm{RNA}$ was compared with that of the mRNA for GAP-43. GAP-43 is a neuronal protein that is associated with outgrowth, maintenance, and modification of axonal nerve terminals (for reviews, see Benowitz and Routtenberg, 1987; Skene, 1989). In the nervous system of the rat, BC1 RNA and GAP-43 mRNA have been shown to be coexpressed in many types of neurons (Tiedge et al., 1991; $\mathrm{H}$. Tiedge and J. Brosius, unpublished observations). Figure $3 B$ shows that in the human retina, GAP-43 mRNA labeling was evident in cells of the ganglion cell layer. Only minor labeling was observed in the inner nuclear layer. Other layers, including the inner plexiform layer, showed little or no specific labeling. These results suggest that BC200 RNA and GAP- 43 mRNA are expressed by the same types of neurons in the human retina; however, while BC200 RNA extends into the dendritic fields of these neurons, GAP-43 mRNA is largely confined to layers that contain neuronal somata.

Similar observations were made in the hippocampus (Fig. 4A$F)$. BC200 RNA was detectable throughout Ammon's horn, in a slightly increasing gradient from the CA1 field to the CA3 field. Silver grains were seen overlying the layer of pyramidal cell bodies and the territory of their dendrites. Neurons of the hilar region were also strongly labeled. In dentate granule cells, the labeling signal was lower than in Ammon's horn. GAP-43 mRNA labeling paralleled that of BC200 RNA, with high signals in Ammon's horn and in the hilar region. Slightly lower labeling intensities were observed in dentate granule cells (see also Neve et al., 1988). As in the retina, silver grains indicating the presence of GAP-43 mRNA were largely restricted to neuronal perikarya. It is interesting to note that although the labeling signals for both BC200 RNA and GAP-43 mRNA were only moderate in dentate granule cells, they seem to be higher than in equivalent cells in rat where neither BC1 RNA nor GAP-43 mRNA is detectable at significant levels (Rosenthal et al., 1987; H. Tiedge and $\mathbf{J}$. Brosius, unpublished observations).

High levels of BC200 RNA were also expressed in the neocortex (Fig. 4G). Strong labeling was seen in layers II, III, V, and VI; in other layers, the signal was weaker, but still appreciably above background. Significant labeling in layer I (which is scarcely populated by neuronal cell bodies) is again indicative of a dendritic location of BC200 RNA. Little or no specific labeling was observed in white matter areas. Although comparable observations were made in other areas of the human neocortex (not shown), it remains to be determined in a more comprehensive study whether relative labeling intensities in individual cortical layers may vary from area to area.

\section{Discussion}

We have isolated a number of overlapping cDNA clones that have been derived from human BC200 RNA. The colinearity of these clones - with the exception of homopolymeric sequences-indicates that the RNA is transcribed from only one or a few genes. This is further supported by the fact that only two bands corresponding to BC200 RNA were identified on genomic DNA blots at high stringency. Recent sequence analysis of genomic clones indeed suggests that of three BC200 RNA genes that were examined in the human genome, one is an active gene while the other two are transcriptionally silent pseudogenes (J. A. Martignetti and J. Brosius, unpublished observations). Of the two pseudogenes, only one exhibits sufficient sequence similarity with the unique regions of the true gene to be identified in genomic DNA blots at high stringency (see Fig. 1C).

The $5^{\prime}$ part of BC200 RNA shares $89 \%$ sequence similarity with a stretch of 133 nucleotides comprising the left monomer of Alu-J repetitive elements in the human genome (Jurka and Milosavljevic, 1991). It also shares sequence similarity with human SRP RNA: $86 \%$ similarity between positions $2-82$ in BC200 RNA and a stretch of 79 nucleotides in the 5' part of SRP RNA, and $90 \%$ similarity between positions $87-115$ in BC200 RNA and a stretch of 29 nucleotides in the $3^{\prime}$ part of SRP RNA (Ullu et al., 1982; see also Watson and Sutcliffe, 1987; sequence similarity determined according to Devereux et al., 1984; default settings, gap weight 5.0, length weight 0.3 ). Sequence comparison of SRP RNAs and Alu elements from different species has led to the suggestion that SRP RNA has given rise to the family of Alu elements in mammalian genomes, conceivably in a multistep process that included retroposition events (Ullu and Tschudi, 1984). Our sequence data indicate that the 5' part of BC200 RNA has in turn been derived from an Alu element. After retroposition, sequences downstrcam of the integration site may have been incorporated as the central and $3^{\prime}$ parts of the $\mathrm{BC} 200 \mathrm{RNA}$ gene, with other flanking regions acting as putative upstream and/or downstream regulatory elements. Such a chain of events would support the view that retroposition is an important evolutionary factor that may play a crucial role in the generation of novel genes and gene products (Brosius, 1991; Brosius and Gould, 1992).

Parts of the central A-rich domain and of the $3^{\prime}$ unique domain of BC200 RNA exhibit moderate sequence similarity with the corresponding domains in rat BC1 RNA: the distal sequences [positions 134-187 in BC200 RNA (54 nucleotides) vs. positions 101-149 in BCl RNA] show 91\% similarity (determined according to Devereux et al., 1984; gap weight 2.0, length weight 0.3). Except for consensus elements corresponding to boxes $A$ and $\mathrm{B}$ of the split RNA polymerase III promoter (Galli et al., 1981), the 5' part of rat BCI RNA shares little sequence similarity with BC200 RNA or with either SRP RNA or Alu elements. BC1 RNA is likely to have evolved from tRNA ${ }^{\text {Ala }}$ (Daniels and Deininger, 1985; Lawrence et al., 1985; Sakamoto and Okada, 1985; DeChiara and Brosius, 1987). SRP RNA is the original progenitor of $\mathrm{BC} 200 \mathrm{RNA}$, via an Alu element (probably a monomeric free left arm, FLAM) as an evolutionary intermediate. Thus, the evolution of rodent $\mathrm{BC} 1 \mathrm{RNA}$ and primate BC200 RNA has apparently proceeded via separate phylogenetic routes. Despite their different evolutionary histories, however, BC1 RNA and BC200 RNA share short segments of 

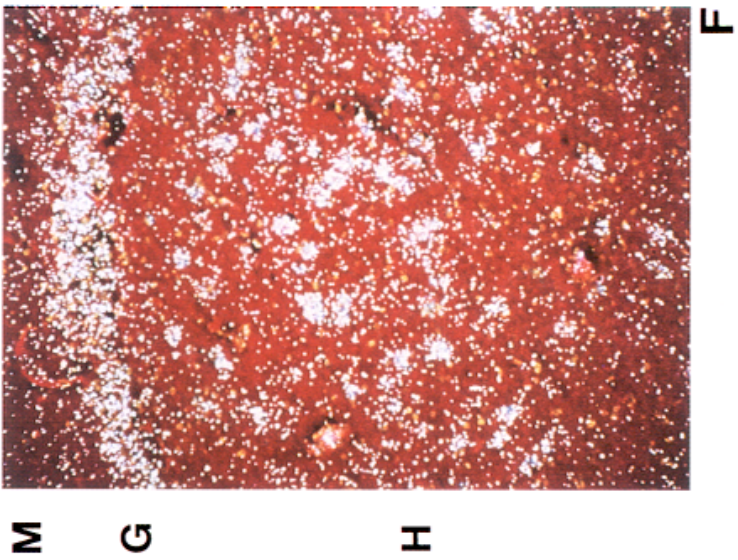

I
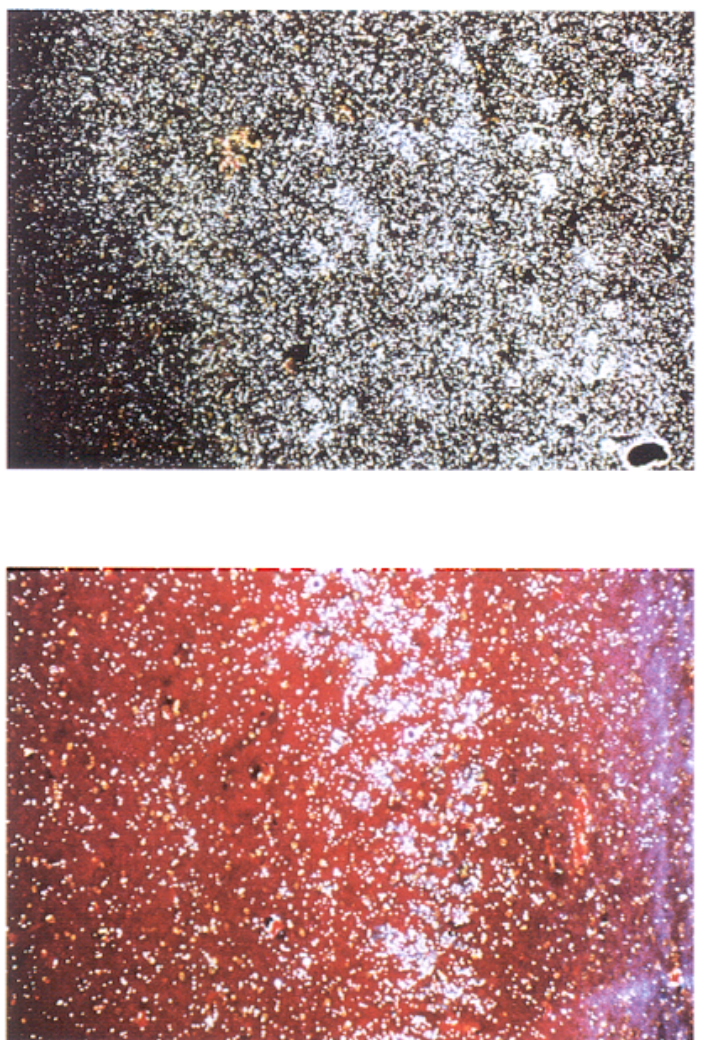
$\frac{}{4}$
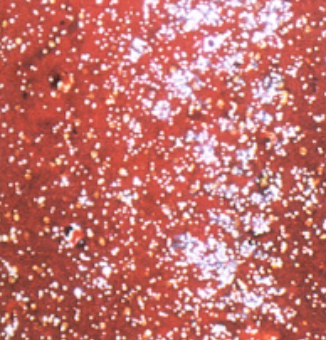

$\simeq$

0
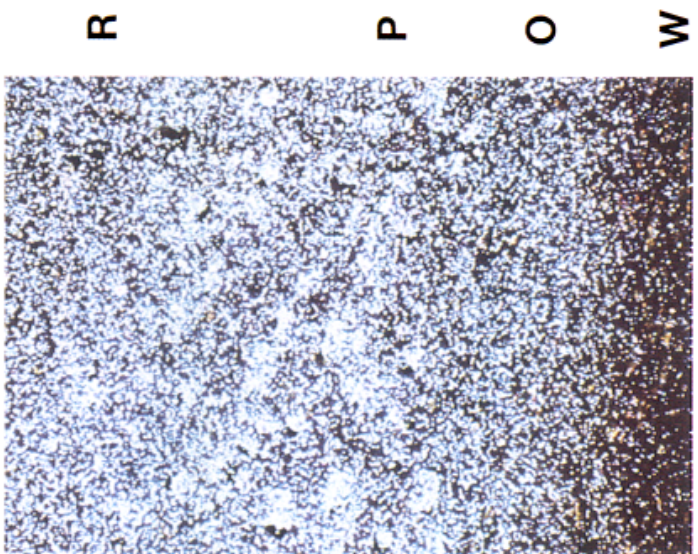
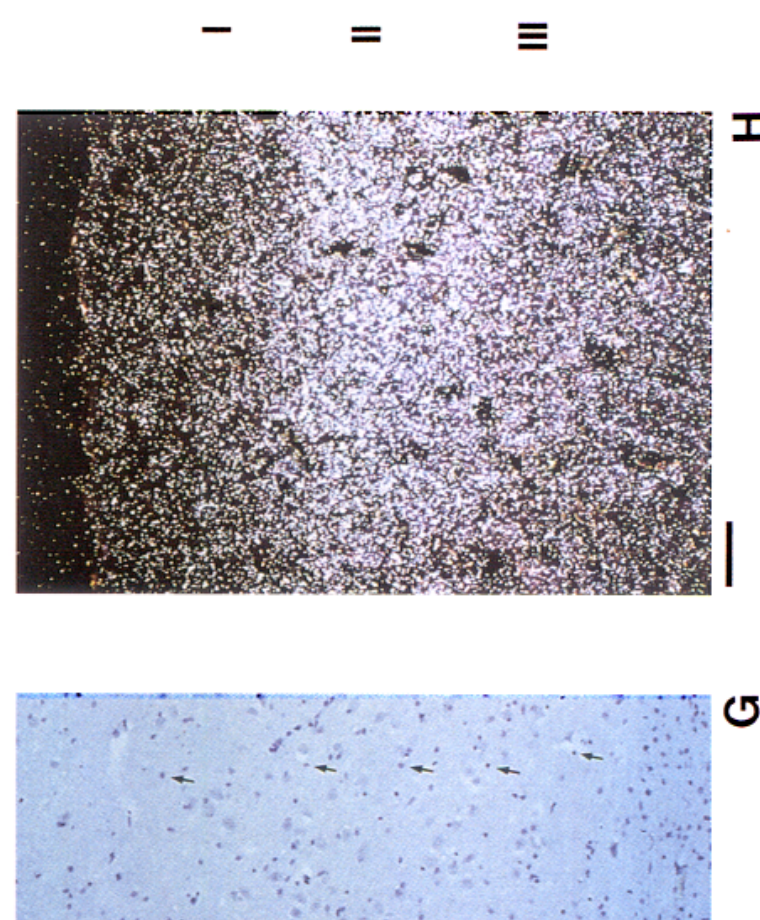

0

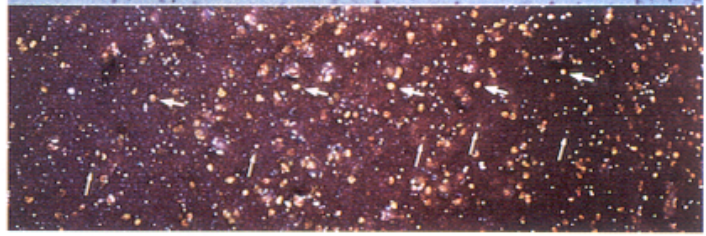

$\simeq$
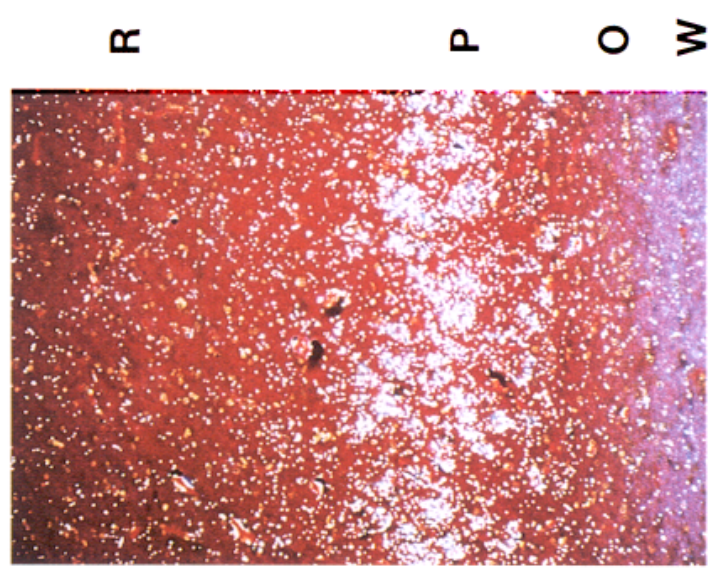

$\simeq$

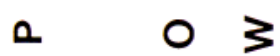

$\varangle$

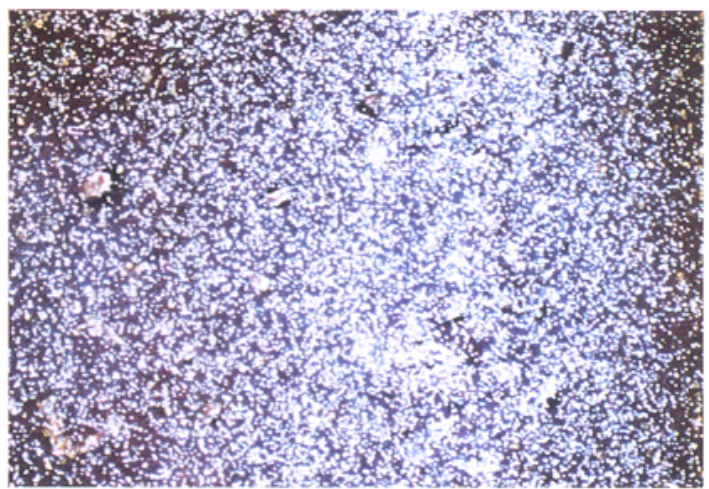

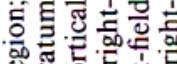

造䜤

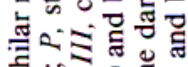

च

.

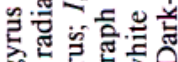

品

零

可䜤

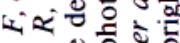

F

is 0

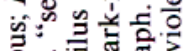

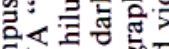

是更过

的.

응월

F

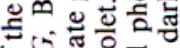

낭

o

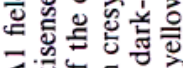

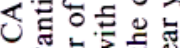

心

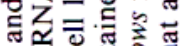

0 은

을

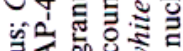

엉

的的政

을 椐的

을

o

o 0 .

o

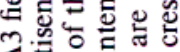

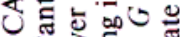

$\infty$ 至.

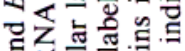

주을

论

论

on

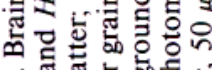

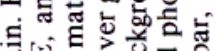

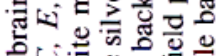

可

要这

을

a.

$4 \times$

乙

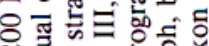

응 0 .

ट्ये $=$

+ . क

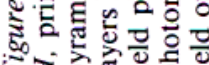


limited sequence similarity (which are sufficient for cross-hybridization at low stringency). Such sequence elements may confer special functions to the RNAs, for example, the capacity to bind specific proteins or to interact with other RNAs.

Human BC200 RNA is, like the rat counterpart BC1 RNA, selectively expressed in the nervous system. The expression patterns of both RNAs are, to the extent that they have been investigated, strikingly similar. Thus, BC200 RNA and BCl RNA seem to be expressed by equivalent subsets of neurons in the human and rat nervous system, respectively. For example, both BC1 RNA and BC200 RNA are expressed by retinal ganglion cells, whereas only negligible amounts of either RNA are found in photoreceptor cells. Similarly, in the hippocampus, both RNAs are expressed at high levels by pyramidal cells in Ammon's horn and in the hilar region. Moreover, both in the retina and in the hippocampus, the expression patterns of BC200 RNA and GAP43 mRNA seem to overlap extensively, similar again to the situation in rat (Tiedge et al., 1991; Tiedge and Brosius, unpublished obesrvations). The coexpression of GAP-43 mRNA and $\mathrm{BC} 200$ RNA in certain types of neurons is intriguing, as GAP-43 has been found earlier to be selectively expressed in associative regions of the human brain (Neve et al., 1988).

Significant BC200 labeling in dendrite-rich neuropil areas suggests that this RNA, again like rat BCl RNA, is located in somatodendritic domains. Thus, the similar anatomical and subcellular distribution of human BC200 RNA and rat $\mathrm{BC} 1$ RNA is indicative of equivalent functional roles of these RNAs, in primates and rodents, respectively, in postsynaptic domains of various types of neurons. In view of their independent evolutionary histories, we would therefore classify these RNAs as functional analogs (rather than as homologs). Analogous secondary structures, although not immediately apparent from the primary sequences, may be potentially crucial for the functional roles of these RNAs. In addition, short stretches of limited sequence similarity may be vital for RNA-protein interactions that are central to the function of RNPs. The notion that the functional unit is a specific RNP has recently received support from experimental data showing that $\mathrm{BC} 1 \mathrm{RNA}$ is indeed complexed with proteins in vivo (Kobayashi et al., 1991, 1992; Cheng et al., 1992). In the context of dendritic protein synthesis, such an RNP may assist in translation-related processes such as the dendritic transport and targeting of mRNAs (or, alternatively, of polyribosomes) or the arrest and reinitiation of postsynaptic translation, for example, as a function of synaptic activity. In the SRP, the protein heterodimer SR P 9/14 is required for translational arrest (Siegel and Walter, 1985). A sequence element similar to the SRP RNA consensus motif that is responsible for binding of this heterodimer (Strub et al., 1991) is present in BC200 RNA. It is expected that the identification of human BC200 RNA will facilitate the isolation of the BC200 RNP and the eventual understanding of its functional significance.

\section{References}

Benowitz LI, Routtenberg A (1987) A membrane phosphoprotein associated with neural development, axonal regeneration, phospholipid metabolism, and synaptic plasticity. Trends Neurosci 10:527531.

Benson DL, Isackson PJ, Gall CM, Jones EG (1991) Differential effects of monocular deprivation on glutamic acid decarboxylase and type II calcium-calmodulin-dependent protein kinase gene expression in the adult monkey cortex. J Neurosci 11:31-47.
Bogenhagen DF, Brown DD (1981) Nucleotide sequence in Xenopus 5S DNA required for transcription termination. Cell 24:261-270.

Brosius J (1991) Retroposons-seeds of evolution. Science 251:753.

Brosius J, Gould SJ (1992) On "genomenclature": a comprehensive (and respectful) taxonomy for pseudogenes and other "junk DNA." Proc Natl Acad Sci USA 89:10706-10710.

Bruckenstein DA, Lein PJ, Higgins D, Fremeau RT Jr (1990) Distinct spatial localization of specific mRNAs in cultured symapthetic neurons. Neuron 5:809-819.

Burgin KE, Waxham MN, Rickling S, Westgate SA, Mobley WC, Kelly PT (1990) In situ hybridization histochemistry of $\mathrm{Ca}^{2+} /$ calmodulindependent protein kinase in developing rat brain. J Neurosci 10:17881798.

Cheng JG, Tiedge H, Brosius J (1992) Characterization of BCl scRNP, a brain-specific cytoplasmic ribonucleoprotein complex. Soc Neurosci Abstr 18:624.

Chicurel ME, Terrian DM, Harris KM, Potter H (1991) mRMA at the synapse: analysis of a preparation enriched in hippocampal dendritic spine mRNA. Soc Neurosci Abstr 17:379.

Church GM, Gilbert W (1984) Genomic sequencing. Proc Natl Acad Sci USA 81:1991-1995.

Cleveland DW (1990) Microtubule MAPing. Cell 60:701-702.

Daniels GR, Deininger PL (1985) Repeat sequences derived from mammalian tRNA genes. Nature 317:819-822.

Davis L, Banker G, Steward O (1987) Selective dendritic transport of RNA in hippocampal neurons in culture. Nature 330:477-479.

Davis L, Burger B, Banker G, Steward O (1990) Dendritic transport: quantitative analysis of the time course of somatodendritic transport of recently synthesized RNA. J Neurosci 10:3056-3068.

DeChiara TM, Brosius J (1987) Neural BC1 RNA: cDNA clones reveal nonrepetitive sequence content. Proc Natl Acad Sci USA 84:26242628.

Devereux J, Haeberli P, Smithies O (1984) A comprehensive set of sequence analysis programs for the VAX. Nucleic Acids Res 12:387395.

Devlin PE, Ramachandran KL, Cate RL (1988) Southern analysis of genomic DNA with unique and degenerate oligonucleotide probes: a method for reducing probe degeneracy. DNA 7:499-507.

Dowling JE, Boycott BB (1966) Organization of the primate retina: electron microscopy. Proc R Soc Lond [Biol] 166:80-111.

Dugich-Djordjevic MM, Tocco G, Willoughby DA, Najm I, Pasinetti G, Thompson RF, Baudry M, Lapchak PA, Hefti F (1992) BDNF mRNA expression in the developing rat brain following kainic acidinduced seizure activity. Neuron 8:1127-1138.

Feramisco JR, Smart JE, Burridge K, Helfman DM, Thomas GP (1982) Co-existence of vinculin and a vinculin-like protein of higher molecular weight in smooth muscle. J Biol Chem 257:11024-11031.

Fremeau RT Jr, Autelitano DJ, Blum M, Wilcox J, Roberts JL (1989) Intervening sequence-specific in situ hybridization: detection of the pro-opiomelanocortin gene transcript in individual neurons. Mol Brain Res 6:197-201.

Frohman MA, Dush MK, Martin GR (1988) Rapid production of full-length cDNAs from rare transcripts: amplification using a single gene-specific oligonucleotide primer. Proc Natl Acad Sci USA 85: 8998-9002.

Galli G, Hofstetter H, Birnstiel ML (1981) Two conserved sequence blocks within eukaryotic tRNA genes are major promoter elements. Nature 294:626-631.

Garner CC, Tucker RP, Matus A (1988) Selective localization of messenger RNA for cytoskeletal protein MAP2 in dendrites. Nature 336: 674-677.

Greenough WT, Hwang H-MF, Gorman C (1985) Evidence for active synapse formation or altered postsynaptic metabolism in visual cortex of rats reared in complex environments. Proc Natl Acad Sci USA 82: $4549-4552$.

Hof PR, Morrison JH (1990) Quantitative analysis of a vulnerable subset of pyramidal neurons in Alzheimer's disease: II. Primary and secondary cortex. J Comp Neurol 301:55-64.

Jurka J, Milosavljevic A (1991) Reconstitution and analysis of human Alu genes. J Mol Evol 32:105-121.

Jurka J, Zuckerkandl E (1991) Free left arms as precursor molecules in the evolution of Alu sequences. J Mol Evol 33:49-56.

Kennedy MB (1989) Regulation of synaptic transmission in the central nervous system: long-term potentiation. Cell 59:777-787.

Kleiman K, Banker G, Steward O (1990) Differential subcellular lo- 
calization of particular mRNAs in hippocampal neurons in culture. Neuron 5:821-830.

Kobayashi S, Goto S, Anzai K (1991) Brain-specific small RNA transcript of the identifier sequences is present as a $10 \mathrm{~S}$ ribonucleoprotein particle. J Biol Chem 266:4726-4730.

Kobayashi S, Higashi N, Susuki K, Goto S, Yumoto K, Anzai K (1992) The $10 \mathrm{~S} \mathrm{BC}-1$ ribonucleoprotein particle contains identifier sequence-binding proteins that interact with an array of GCAAG/ CTTGC motifs between split promoter sequences for RNA polymerase III. J Biol Chem 267:18291-18297.

Lawrence CB, McDonnell DP, Ramsey WJ (1985) Analysis of repetitive sequence elements containing tRNA-like sequences. Nucleic Acids Res 13:4239-4252.

McKinnon RD, Danielson P, Brow MAD, Bloom FE, Sutcliffe JG (1987) Expression of small cytoplasmic transcripts of the rat identifier element in vivo and in cultured cells. Mol Cell Biol 7:2148-2154.

Neve RL, Finch EA, Bird ED, Benowitz LI (1988) Growth-associated protein GAP-43 is expressed selectively in associative regions of the adult rat brain. Proc Natl Acad Sci USA 85:3638-3642.

Papandrikopoulou A, Doll T, Tucker RP, Garner CC, Matus A (1989) Embryonic MAP2 lacks the cross-linking sidearm sequences and dendritic targeting signal of adult MAP2. Nature 340:650-652.

Quentin Y (1992) Origin of the Alu family: a family of Alu-like monomers gave birth to the left and the right arms of the Alu elements. Nucleic Acids Res 20:3397-3401.

Ramón y CajalS (1892) La rétine des vertébrés. La Cellule 9 [translated as: The structure of the retina (Thorpe SA, Glickstein $M$, transls), 1972]. Springfield: Thomas.

Rao A, Steward O (1991) Evidence that protein constituents of postsynaptic membrane specializations are locally synthesized: analysis of proteins synthesized within synaptosomes. J Neurosci 11:28812895.

Rosenthal A, Chan SY, Henzel W, Haskell C, Kuang W-J, Chen E, Wilcox JN, Ullrich A, Goeddel DV, Routtenberg A (1987) Primary structure and mRNA localization of protein F1, a growth-related protein kinase $\mathrm{C}$ substrate associated with synaptic plasticity. EMBO J 6:3641-3646.

Sakamoto K, Okada N (1985) Rodent type 2 Alu family, rat identifier sequence, rabbit $\mathrm{C}$ family, and bovine or goat 73-bp repeat may have evolved from tRNA genes. J Mol Evol 22:134-140.

Sambrook J, Fritsch EF, Maniatis T (1989) Molecular cloning. A laboratory manual, 2d Ed. Cold Spring Harbor, NY: Cold Spring Harbor Laboratory.

Sanger F, Nicklen S, Coulson $\Lambda R$ (1977) DN $\Lambda$ sequencing with chain terminating inhibitors. Proc Natl Acad Sci USA 74:5463-5467.

Siegel V, Walter $P$ (1985) Elongation arrest is not a prerequisite for secretory protein translocation across the microsomal membrane. $\mathrm{J}$ Cell Biol 100:1913-1921.

Skene JHP (1989) Axonal growth-associated proteins. Annu Rev Neurosci 12:127-156.

Smith CL, Klco SR, Cantor CR (1988) Pulsed field gel electrophoresis and the technology of large DNA molecules. In: Genome analysis: a practical approach (Davies KE, ed), pp 41-72. Oxford: IRL.

Steward O (1983) Alterations in polyribosomes associated with dendritic spines during the reinnervation of the dentate gyrus of the adult rat. J Neurosci 3:177-188.
Steward O, Banker GA (1992) Getting the message from the gene to the synapse: sorting and intracellular transport of RNA in neurons. Trends Neurosci 15:180-186.

Steward O, Falk PM (1986) Protein synthetic machinery at postsynaptic sites during synaptogenesis: a quantitative study of the association between polyribosomes and developing synapses. J Neurosci $6: 412-423$.

Steward O, Levy WB (1982) Preferential localization of polyribosomes under the base of dendritic spines in granule cells of the dentate gyrus. J Neurosci 2:284-291.

Steward O, Reeves TM (1988) Protein-synthetic machinery beneath postsynaptic sites on CNS neurons: association between polyribosomes and other organelles at the synaptic site. J Neurosci 8:176184.

Strong MJ, Svedmyr A, Gajdusek DC, Garruto RM (1990) The temporal expression of amyloid precursor protein mRNA in vitro in dissociated hippocampal neuron cultures. Exp Neurol 109:171-179.

Strub K, Moss J, Walter P (1991) Binding sites of the 9- and 14kilodalton heterodimeric protein subunit of the signal recognition particle (SRP) are contained exclusively in the Alu domain of SRP RNA and contain a sequence motif that is conserved in evolution. Mol Cell Biol 11:3949-3959.

Tiedge H (1991) The use of UV light as a cross-linking agent for cells and tissue sections in in situ hybridization. DNA Cell Biol 10:143147.

Tiedge H, Fremeau RT Jr, Weinstock PH, Arancio O, Brosius J (1991) Dendritic location of neural BC1 RNA. Proc Natl Acad Sci USA 88: 2093-2097.

Toneguzzo F, Glynn S, Levi E, Mjolsness S, Hayday A (1988) Use of chemically modified T7 DNA polymerase for manual and automated sequencing of supercoiled DNA. Biotechniques 6:460-469.

Torre ER, Steward O (1992) Demonstration of local protein synthesis within dendrites using a new cell culture system that permits the isolation of living axons and dendrites from their cell bodies. J Neurosci 12:762-772.

Tucker RP, Garner CC, Matus A (1989) In situ localization of microtubule-associated protein mRNA in the developing and adult rat brain. Neuron 2:1245-1256.

Ullu E, Tschudi C (1984) Alu sequences are processed 7SL RNA genes. Nature 312:171-172.

Ullu E, Weiner AM (1984) Human genes and pseudogenes for the 7SL RNA component of signal recognition particle. EMBO J 3:33033310.

Ullu E, Murphy S, Melli M (1982) IIuman 7SL RNA consists of a 140 nucleotide middle-repetitive sequence inserted in an Alu sequence. Cell 29:195-202.

Walter P, Blobel G (1982) Signal recognition particle contains a $7 \mathrm{~S}$ RNA essential for protein translocation across the endoplasmic reticulum. Nature 229:691-698.

Watson JB, Sutcliffe JG (1987) Primate brain-specific cytoplasmic transcript of the Alu repeat family. Mol Cell Biol 7:3324-3327.

Willard C, Nguyen HT, Schmid CW (1987) Existence of at least three distinct Alu subfamilies. J Mol Evol 26:180-186.

Zwieb C, Nielsen L (1992) The signal recognition particle (SRP) database. Nucleic Acids Res 20:2207. 